\title{
High TCTP expression as prognostic factor in different cancer types
}

\author{
NICOLAS FISCHER ${ }^{1}$, MOHAMED E.M. SAEED ${ }^{1}$, ELENA LIPPE ${ }^{2}$, WILFRIED ROTH $^{2}$ and THOMAS EFFERTH ${ }^{1}$ \\ ${ }^{1}$ Department of Pharmaceutical Biology, Institute of Pharmaceutical and Biomedical Sciences, Johannes Gutenberg \\ University, D-55128 Mainz; ${ }^{2}$ Department of Pathology, University Medical Center, D-55131 Mainz, Germany
}

Received August 3, 2020; Accepted November 5, 2020

DOI: 10.3892/wasj.2020.74

\begin{abstract}
The translationally controlled tumor protein (TCTP) has been linked to a number of fundamental biological processes, including tumorigenesis and cancer progression. Due to its role in tumor reversion, the interest in TCTP as a therapeutic target is constantly increasing. TCTP has also been discussed as a prognostic factor. However, evaluations of large numbers of different cancer types are still not available. The present study thus investigated the role of TCTP mRNA and protein expression as prognostic factors in different cancer types. The Oncomine database was analyzed for statistical associations between TCTP mRNA and the survival times of 5,651 cancer patients. Additionally, immunohistochemical analyses of 495 tissue samples covering 26 tumor types was performed. The associations between nuclear and cytoplasmic TCTP protein expression and tumor stage, grade, nodal status and metastatic status were also analyzed. Significant associations between a high TCTP mRNA expression and a decreased overall survival were observed in breast, lung, ovarian and prostate cancer. Nuclear and cytoplasmic TCTP protein expression was elevated in 24 cancer types. In kidney cancer, a high TCTP expression was associated with a higher tumor grade, stage, metastatic and nodal status. On the whole, the present study demonstrates that TCTP may serve as a prognostic factor in different tumor types.
\end{abstract}

Correspondence to: Professor Thomas Efferth, Department of Pharmaceutical Biology, Institute of Pharmaceutical and Biomedical Sciences, Johannes Gutenberg University, Staudinger Weg 5, D-55128 Mainz, Germany

E-mail: efferth@uni-mainz.de

Abbreviations: cTCTP, cytoplasmic translationally controlled tumor protein; HRF, histamine releasing factor; $\mathrm{H}_{2} \mathrm{O}_{2}$, hydrogen peroxide; mRNA, messenger ribonucleic acid; nTCTP, nuclear translationally controlled tumor protein; PBS, phosphate-buffered saline; TCTP, translationally controlled tumor protein; TMA, tissue microarrays; TNM, tumor-node-metastasis classification system; TPT1, tumor protein, translationally-controlled 1

Key words: TCTP, cancer, prognosis, immunohistochemistry, expression

\section{Introduction}

The 19-24 kDa translationally controlled tumor protein (TCTP), which is encoded by the TPT1 gene, is evolutionary highly conserved and ubiquitously present in all eukaryotic tissues and cell types (1-3). It is also known as fortilin, p21, p23, Q23 or histamine-releasing factor (HRF) (2). A wide range of interactions with cellular proteins has been reported $(1,4,5)$. TCTP is involved in a number of biological processes, e.g. the cell cycle $(6-8)$, cell growth $(9,10)$ and cellular development $(11,12)$, protein synthesis $(13)$, cytoskeleton $(6,14-16)$, immune response (17-19) and cell death $(20,21)$. It has been associated with carcinogenesis $(22,23)$, but also with tumor reversion $(24,25)$. In tumor reversion, tumor cells lose their malignant phenotype and begin reverting (26). In addition, TCTP has been shown to be the most downregulated protein in revertant cells compared to parental cancer cells $(24,27)$.

Cancer is one of the foremost causes of mortality worldwide (28). The most frequent malignancies in total numbers are lung cancer, breast cancer and prostate cancer (29). Modern cancer treatment is based on surgery, chemotherapy, radiation, immunotherapy, targeted therapy, hormone therapy, stem cell transplantation and combinations of these. However, the majority of these options still lack satisfactory efficiency and are associated with severe side-effects, limiting both the patient's quality of life and the therapeutic success. In particular, drug resistance is challenging in medical oncology (30). The demand for novel drugs against new targets continues to increase.

Targets for cancer therapy are defined as cellular structures with different biological functions and/or expression levels in cancer and normal cells. These changes contribute to malignant transformation, and their pharmacological targeting may lead to tumor suppression. Biological targets for cancer therapy are also valuable prognostic factors for the course of cancer (26).

TCTP overexpression has been reported in cancer $(31,32)$. Notably, Telerman and Amson demonstrated a considerable downregulation of TCTP during the process of tumor reversion (27). Following malignant transformation, tumors retain their ability to be reprogrammed, which initiates the re-differentiation of de-dedifferentiated cells and to stop de-regulated tumor cell growth. Therefore, it is imperative to better understand the cellular and molecular mechanisms initiating 
and regulating tumor reversion and to exploit this surprising phenomenon for therapeutic purposes, in order to inhibit the malignant process and proliferation. However, the relevance of TCTP as a novel target in cancer therapy and particularly, in tumor reversion remains to be clarified.

To date, TCTP has not been extensively investigated as prognostic factor in cancer diseases $(31,33)$. The present study analyzed the association between TCTP and clinical outcome at both the mRNA and protein level on a broad basis. For this purpose, 12 datasets covering 5,651 patients and 8 cancer types were analyzed. In addition, immunohistochemical analyses of 495 cases of 26 tumor types was performed and the association between TCTP protein expression and clinical outcome was also analyzed. This analysis was undertaken as a starting point for the establishment of a novel tumor marker and target for cancer therapy.

\section{Materials and methods}

Statistical evaluation of the Oncomine database. TCTP mRNA expression data was attained from the Oncomine database (https://www.oncomine.org). Only datasets including the expression values of TPT1 (also known as TCTP) were selected. Furthermore, only datasets were selected, where comparative information was available for cancer tissue and their matched normal tissues and where the survival status as clinical outcome parameter was recorded. For reliable statistical evaluation, only datasets with $>151$ samples each were included into the evaluations (Fig. 1). A total of 12 datasets with 8 cancer types from 5,651 samples fulfilled these criteria. Among these were cancers of the bladder, brain, breast (2 sets), colorectal, lung (3 sets), ovarian and prostate, as well as lymphoma. Normalized TCTP expression values were defined as 'low' and 'high' using median and mean as cut-off values. The datasets for time-to-death distributions were analyzed and estimated using Kaplan-Meier curves. The log-rank test was used for significance assignment. IBM SPSS statistics V23 program (IBM, Inc.) was used for all statistical analyses. Statistical differences with P-values $<0.05$ were regarded as significant.

Tumor cases. A total of 495 formalin-fixed and paraffin-embedded tumor cases covered 26 tumor types. The tissue microarrays (TMA) T8235713 (BioCat GmbH) and BC000119 (Biomax Inc.) were commercially available. Further TMAs were provided by the Tissue Bank of the Institute of Pathology, University Medical Center of the Johannes-Gutenberg-Universität, Mainz) with ethical approvals from the Ethics Committee of the State Authorization Association for Medical Issues (Landesärztekammer) Rheinland Pfalz to W.R. (October 2, 2015; Ref. 837.031 9799) and to T.E. (March 22, 2018; Ref. 2018-13179). The patients gave their approval for the evaluation of tumor material and publication of data generated from these investigations prior to participation.

Immunohistochemistry. The immunohistochemical staining protocol used in the present study was as previously described (34). Paraffin was removed by 2 washing steps with xylene (99\%), 5 min each at room temperature. Rehydration was conducted by graded washing steps with isopropanol at various concentrations (100, 96 and 70\%). Slides were washed with PBS and heat-induced epitope-retrieval was performed for $20 \mathrm{~min}$ using hot vapor. The slides were incubated in $3 \%$ $\mathrm{H}_{2} \mathrm{O}_{2}$ for $10 \mathrm{~min}$ at room temperature to avoid chromogen binding and endogen peroxidase. Following $5 \mathrm{~min}$ of PBS washing, UltraVision Protein Block and UltraVision Hydrogen Peroxidase Block (Thermo Fisher Scientific, Inc.) were added for $20 \mathrm{~min}$ for the blockade of endogenous proteins and endogenous peroxidase to reduce non-specific background staining. Primary TPT1 (TCTP) antibody (1:300 dilution; PA5-35332, Thermo Fisher Scientific, Inc.) was added followed by incubation at $4^{\circ} \mathrm{C}$ for $12 \mathrm{~h}$. After washing, horseradish-peroxidase-labeled polymers (1:100 dilution; TL-060-QPB, Thermo Fisher Scientific, Inc.) were added for $1 \mathrm{~h}$ at room temperature according to the manufacturer's protocol. Before counterstaining with hematoxylin for $3 \mathrm{~min}$ at room temperature, diaminobenzidine (DAB Quanto Chromogen, 1:30 dilution; TA-002-QHCX, Thermo Fisher Scientific, Inc.) was added for $5 \mathrm{~min}$ at room temperature as a final staining step. The slides were dehydrated by grading steps with ethanol at various concentrations (70, 96 and 99\%) and xylol followed by embedding in Entellan (Merck KGaA). Negative control staining (cervix carcinoma) was performed to assure the specificity of the staining process. Immunohistochemical analysis of membrane-bound and nuclear expression of TCTP was performed by 3D Histotech Digital Slide Scanner (3DHISTECH Ltd.). For representative expression values, 6 different areas were selected from each probe. The expression of TCTP was quantified using Pannoramic Viewer software version 1.15 (3DHISTECH Ltd., Budapest, Hungary) using the $\mathrm{H}$-score. A total of 7 cases were excluded due to high necrotic damage and thus insufficient interpretability.

Statistical analysis. One-way ANOVA was used to obtain the mean comparison of TCTP H-score within different cancer types. Variations in the distribution of the TCTP H-score were determined by the Tukey-Kramer's test. TCTP was categorized into 4 degrees of positive or negative groups according to intensity of stain and thus expression. As for the TCTP H-scores, values $>200$ were grouped as strongly positive, whereas $\mathrm{H}$-scores ranging from 100 to 200 were grouped as moderately positive. $\mathrm{H}$-scores ranging between 20 and 100 were grouped as weakly positive, and $\mathrm{H}$-scores $<20$ were considered as negative. An ANOVA mean comparison test for the nTCTP H-score, TNM stage and grade was first performed. Subsequently, the independence of the $\mathrm{H}$-score as a negative or positive group with TNM stage and grade was then determined by the Tukey-Kramer's test. IBM SPSS statistical V23 software (IBM, Inc.) was used for all statistical analyses. Statistical differences with P-values $<0.05$ were regarded as significant.

\section{Results}

Oncomine: Association of TCTP $m R N A$ expression and the survival of cancer patients. A total of 12 datasets of 8 cancer types with 5,651 samples from the Oncomine database was screened with the filter settings mentioned above. The workflow is displayed in Fig. 1. The mean cut-off value revealed 


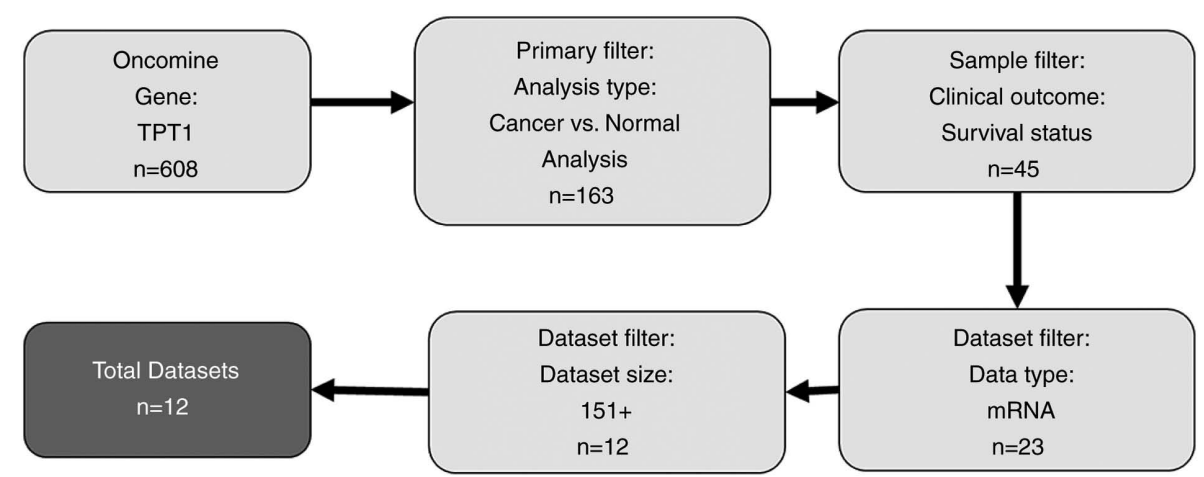

Figure 1. Workflow for dataset screening in the present study.
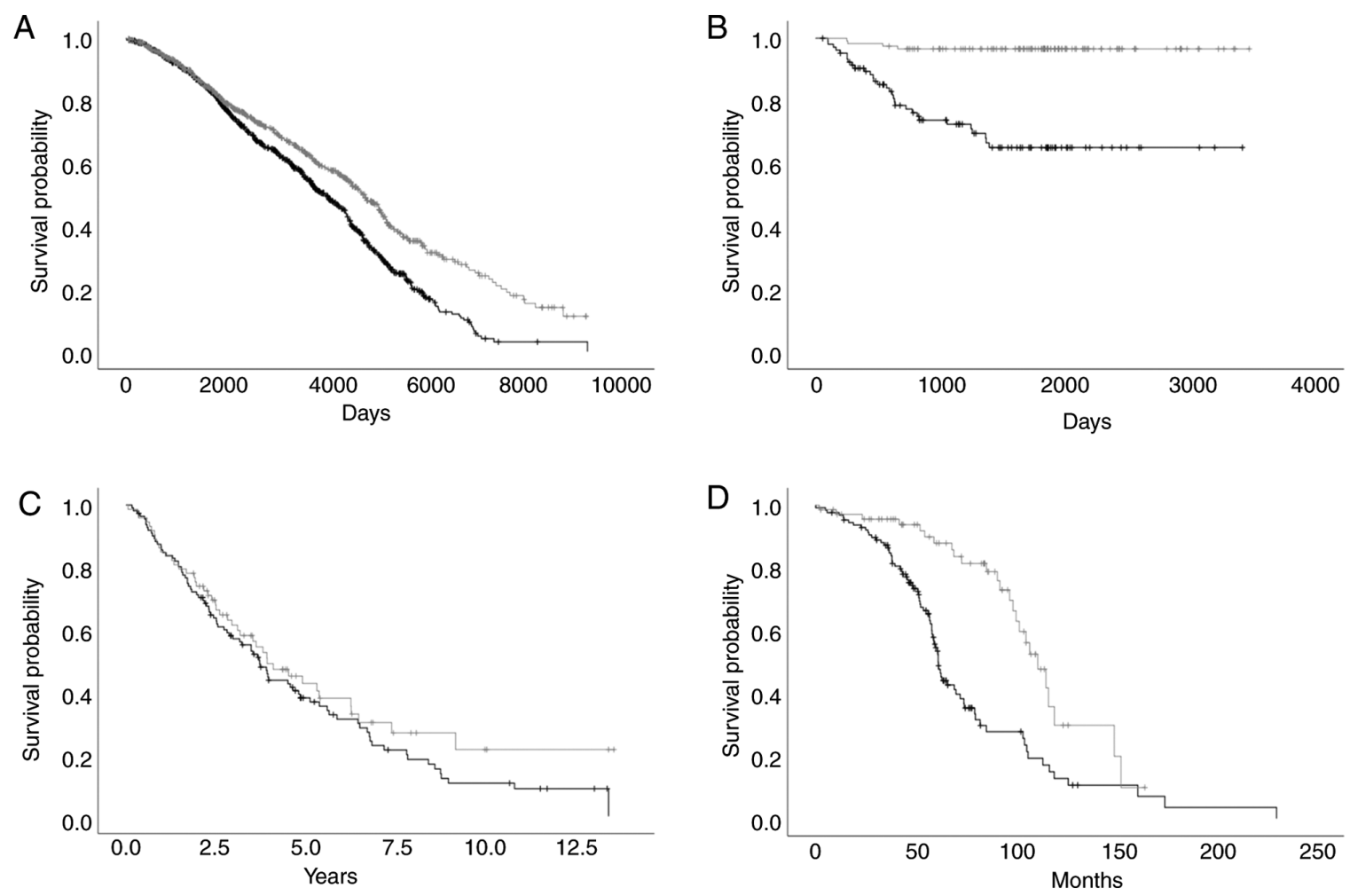

Figure 2. Median cut-off Kaplan-Meier survival analysis of the Oncomine datasets. Low TCTP expression is represented by grey color and high TCTP expression is represented by black color. Survival is presented for (A) Curtis breast carcinoma (days), (B) Okayama lung carcinoma (days), (C) Bonome ovarian carcinoma (years), (D) Taylor prostate carcinoma (months). TCTP, translationally controlled tumor protein.

a significant $(\mathrm{P}<0.05)$ association between the TCTP mRNA level and clinical outcome in 5 datasets out of the 12 examined (41.7\%). A significantly reduced overall survival time was associated with high TCTP mRNA expression levels in the datasets 'Curtis Breast' $(-8.60 \%$; $\mathrm{P}<0.001)$, 'Okayama Lung' (-27.08\%; $\mathrm{P}<0.001)$, 'Bonome Ovarian' (-17.03\%; $\mathrm{P}=0.042)$, 'TCGA Ovarian' (-18.93\%; $\mathrm{P}=0.019)$ and 'Taylor Prostate' $(-30.10 \%$; $\mathrm{P}<0.001)$ (Table I and Fig. 2). The median cut-off value also revealed a statistically significant association between the TCTP mRNA level and clinical outcome in 5 out of 12 (41.7\%) datasets examined: 'Curtis Breast' (-17.84\%; $\mathrm{P}<0.001)$, 'Okayama Lung' (-25.13\% $\mathrm{P}<0.001)$, 'Rosenwald Lymphoma' (-37.89\%; $\mathrm{P}=0.016$, 'TCGA Ovarian' $(-22.16 \%$; $\mathrm{P}=0.008)$ and 'Taylor Prostate' $(-33.79 \%$; $\mathrm{P}<0.001)$ (Table I). A significant association between high TCTP mRNA expression levels and a poor overall survival was observed. Adverse effects were not observed in the given datasets.

The present study did not only wish to determine whether TCTP mRNA expression was associated with the survival times of the patients, but also whether TCTP protein expression was of prognostic value.

Association of TCTP protein expression and pathological parameters. Immunohistochemical investigations of 495 cases derived from 26 tumor types were conducted for the evaluation of the effects of TCTP protein expression on clinical parameters, particularly regarding nuclear (nTCTP) or cytoplasmic expression (cTCTP). The frequency of strong, moderate, weak and negative staining was $12.35,18.04,4.34$ and $28.05 \%$ for nTCTP, and 6.09, 14.68, 17.13 and $20.17 \%$ for cTCTP (data 


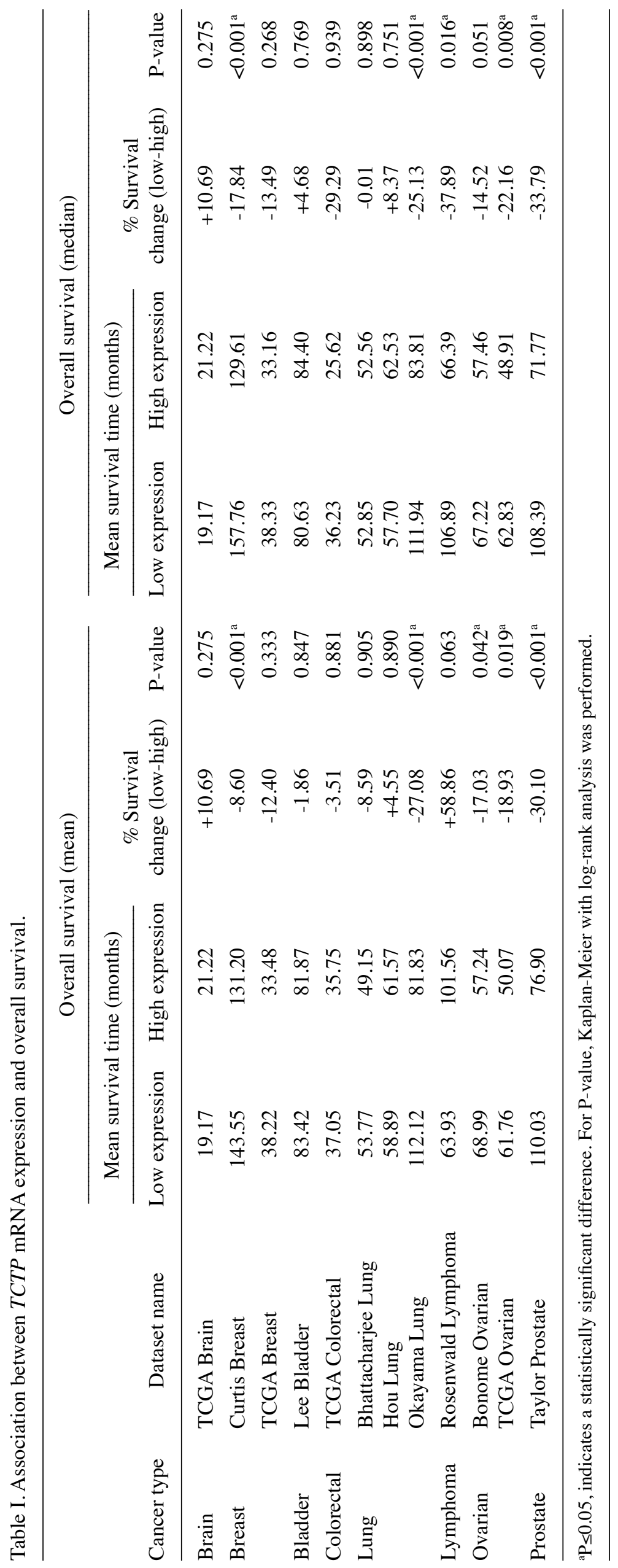


A

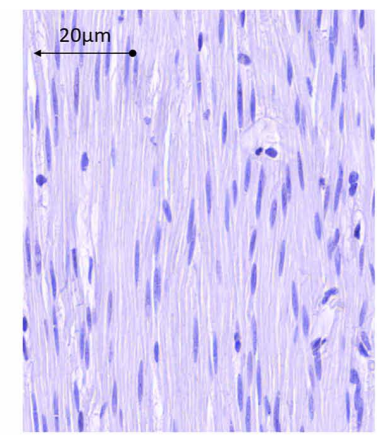

$\mathrm{D}$

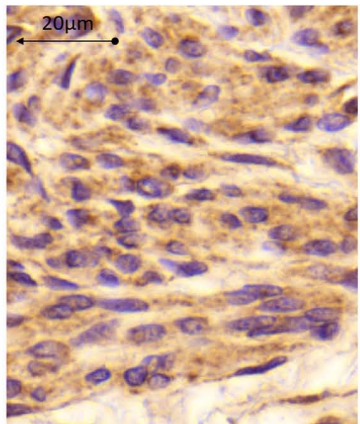

G

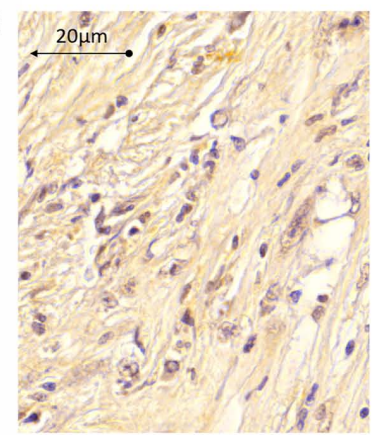

$\mathrm{J}$

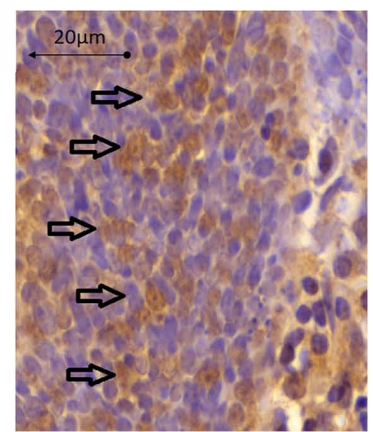

B

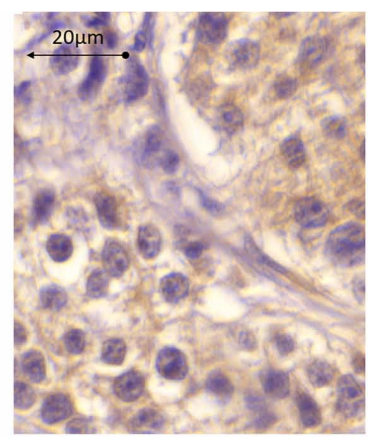

E

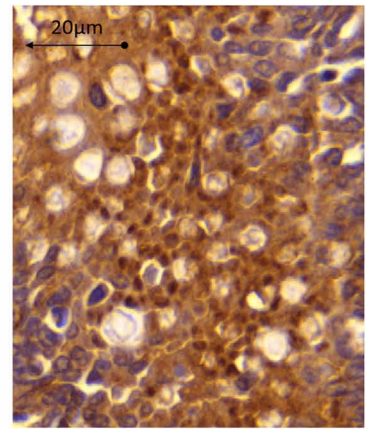

$\mathrm{H}$

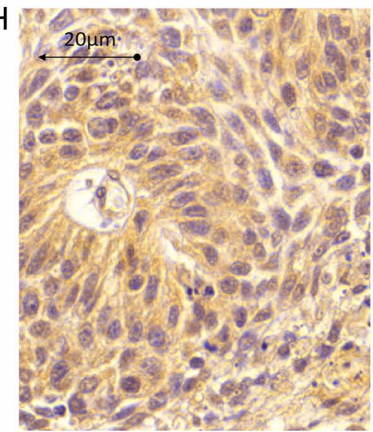

$\mathrm{K}$

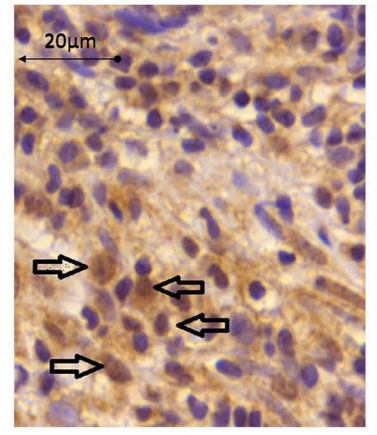

C

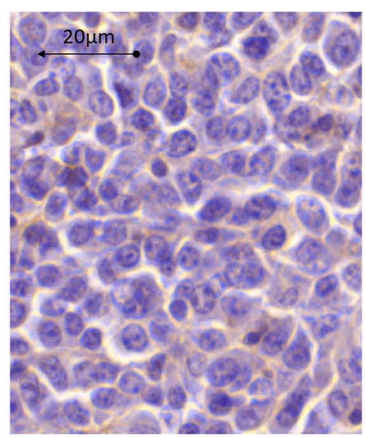

F

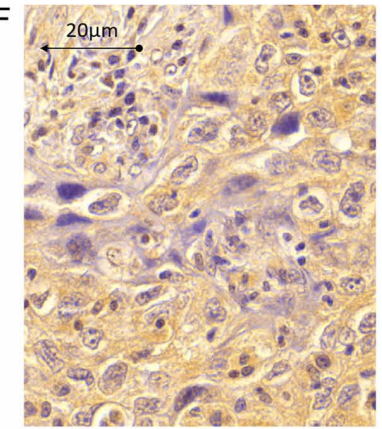

I
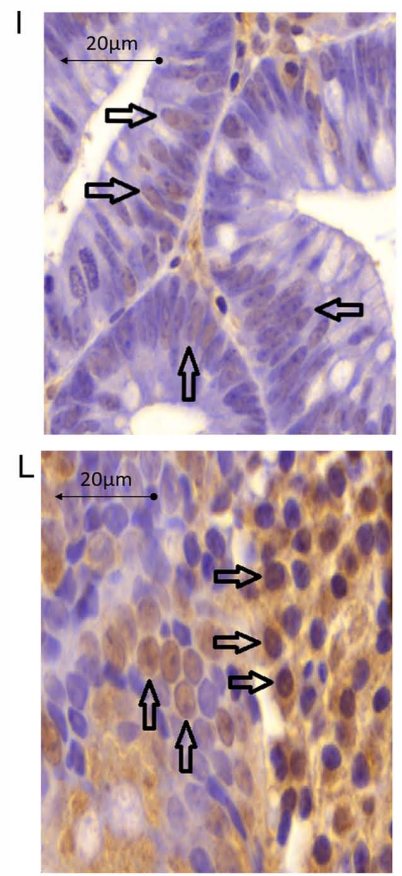

Figure 3. Immunohistochemical detection of TCTP in various tumor types. (A) Negative control staining of a colon tumor. Cytoplasmic TCTP expression in carcinomas of (B) breast; (C) cervix; (D and E) kidney; (F) lung; (G) pancreas; and (H) prostate. Nuclear TCTP expression in carcinomas of (I) colon and (J) lung. Mixed cytoplasmic and nuclear TCTP expression in (K) colon carcinoma and (L) prostate. Staining intensities were scored as weak (C, G and I) moderate [B, D, F, H and K (cytoplasmic)] or strong [E, J, K (nuclear) and L]. Magnification, x20. TCTP, translationally controlled tumor protein.

not shown). Typical expression patterns are illustrated in Fig. 3. The distribution of nTCTP and cTCTP expression was observed in different tumor types.

In all samples analyzed, the cTCTP levels were elevated compared to corresponding normal tissue of the same origin. The present study investigated adipose (liposarcoma), adrenal (pheochromocytoma), bladder (transitional cell carcinoma), brain (meningioma), colon (adenocarcinoma), duodenum (adenocarcinoma), esophagus (squamous cell carcinoma), fallopian tube (adenocarcinoma), gall bladder (adenocarcinoma), kidney (granular cell carcinoma), liver (hepatocellular carcinoma), lung (squamous cell carcinoma), ovary (adenocarcinoma), paratoid (plasmacytoma), prostate (adenocarcinoma), rectum (adenocarcinoma), skin (malignant melanoma), small intestine (Non-Hodgkin's Lymphoma), soft tissue (rhabdomyosarcoma), stomach (adenocarcinoma), testis (seminoma), throat (squamous cell carcinoma), tonsil (squamous cell carcinoma) and uterus (adenocarcinoma) tumorous tissue (Fig. 4). A total of 18 out of 23 tumor types (79.2\%) exhibited an elevated cTCTP expression up to $50 \%$. In duodenal cancer tissue, cTCTP expression was elevated by $61.67 \%$, and in prostate cancer tissue, cTCTP was elevated by $77.65 \%$ compared to 


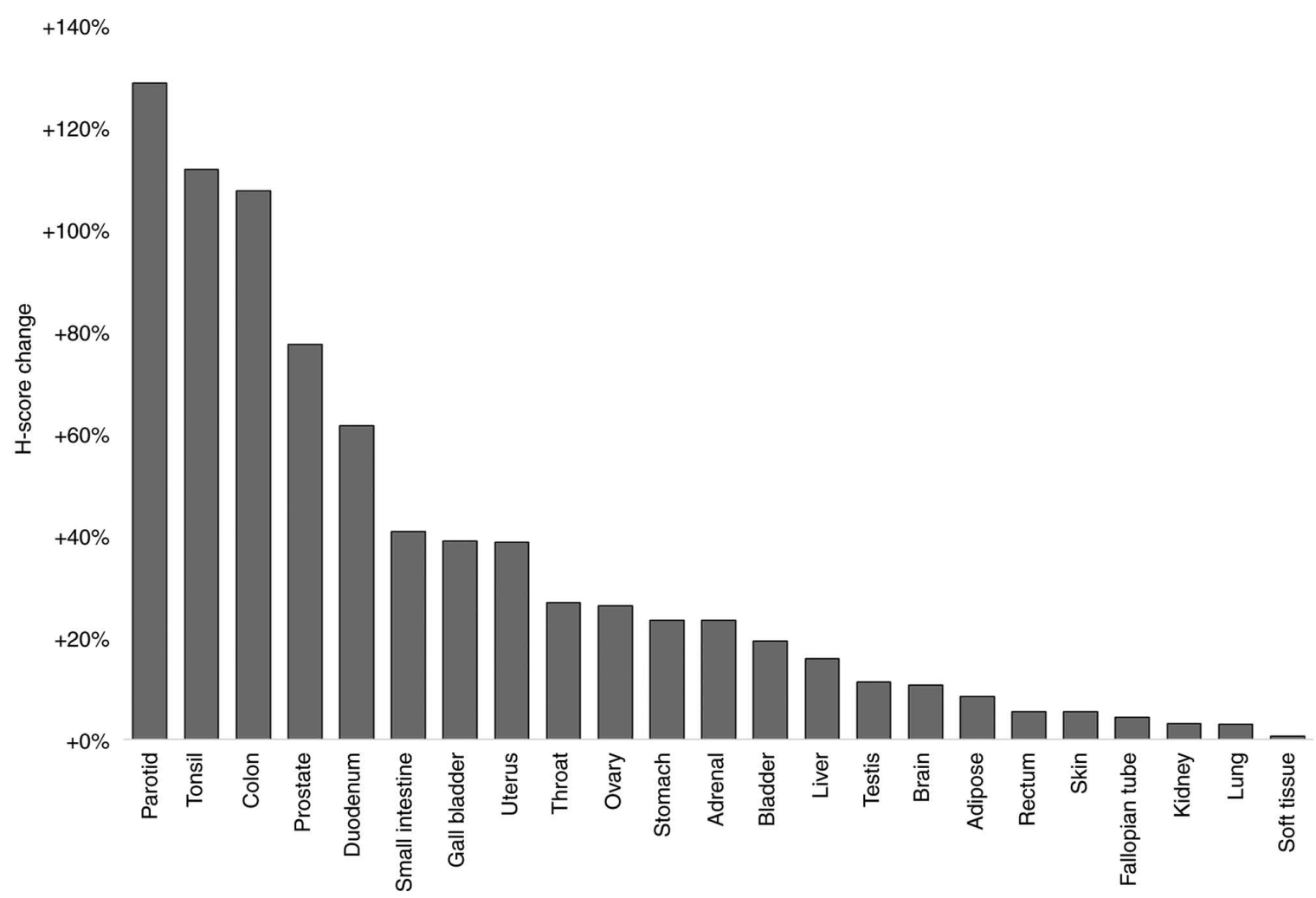

Figure 4. H-score change as an indicator of cytoplasmic TCTP expression in different tumor types compared to normal tissue. TCTP, translationally controlled tumor protein.
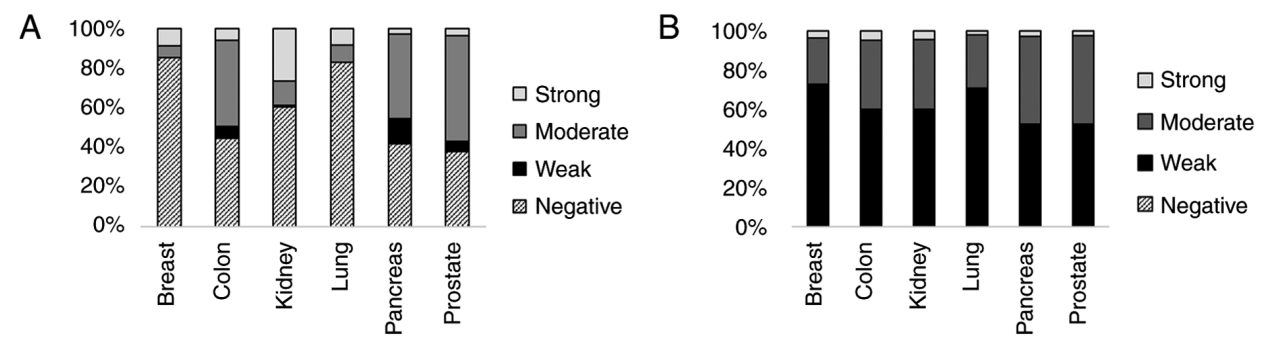

Figure 5. (A) Distribution of nTCTP among different tumor types. (B) Distribution of cTCTP among different tumor types. TCTP levels were classified as 'negative', 'weak', 'moderate' and 'strong'. nTCTP, nuclear translationally controlled tumor protein; cTCTP, cytoplasmic translationally controlled tumor protein.

corresponding normal tissue. In 3 tumor tissues, it was found that cTCTP expression was more than doubled compared to normal tissue. These were colon (107.84\%), tonsil (112.03\%) and paratoid (128.98\%) tumorous tissues (Fig. 4).

Furthermore, the present study investigated the distribution of nTCTP and cTCTP among breast, colon, kidney, lung, pancreas and prostate cancer. As shown in Fig. 5, TCTP expression was not detected in $>40 \%$ of the nuclei of all tissues analyzed. Breast cancer revealed the highest rate of TCTP-negative nuclei (85.32\%), and prostate cancer exhibited the lowest rate of TCTP-negative nuclei (37.83\%). The percentage of nuclei with a strong TCTP expression ranged from $2.86 \%$ (pancreas tumor) to $26.94 \%$ (kidney tumor). Cytoplasmic TCTP was expressed more in all tumor types mentioned above. Of all samples, $>99.08 \%$ exhibited at least a weak cTCTP expression. The ratio of weak cTCTP expression was $>50 \%$ in all samples, and weak and moderate
cTCTP expression was present in $>95 \%$ of all the cancer types analyzed. The ratio of strong cTCTP expression ranged from $1.95 \%$ (lung tumor) to $4.87 \%$ (colon tumor).

Data on tumor stage and tumor grade were available for breast, colon, kidney, lung, pancreas and prostate cancers. The present study evaluated nTCTP expression in those tumor types and their association with the T stage (Fig. 6). Herein, an ANOVA mean comparison test for the nTCTP H-score, TNM stage and grade was first performed. Subsequently, the independence of the H-score as a negative or positive group with TNM stage and grade was then determined by Tukey-Kramer's test.

Nuclear TCTP was similarly expressed in all tumors throughout all stages. For kidney cancer, a slight non-significant increase in nTCTP expression from T1-T4 was observed. Clear conclusions could not be drawn from the results for the other tumor types. As shown in Fig. 7, cTCTP was associated 
A

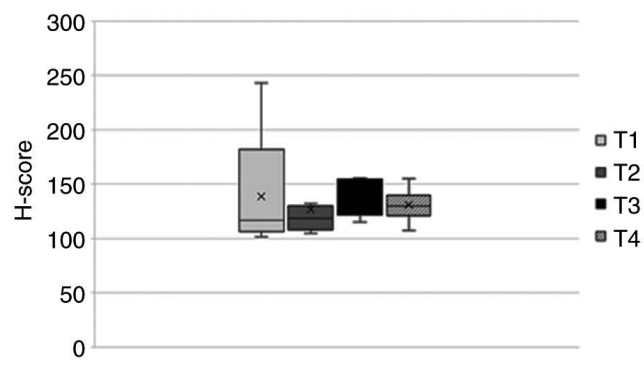

C

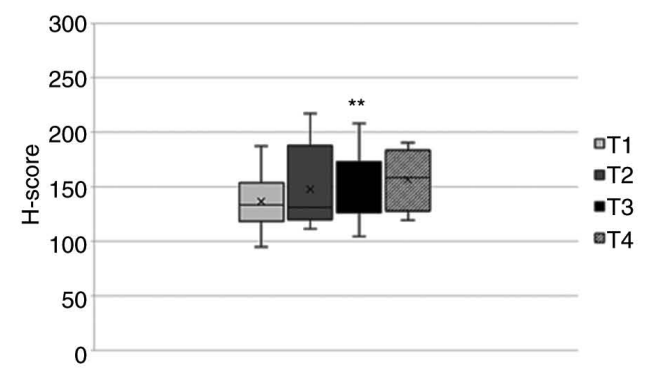

$\mathrm{E}$

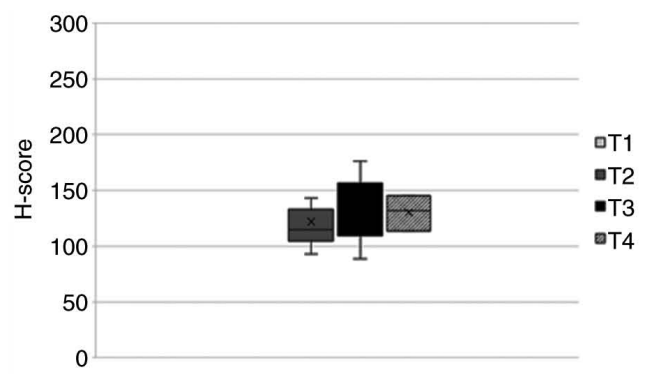

B

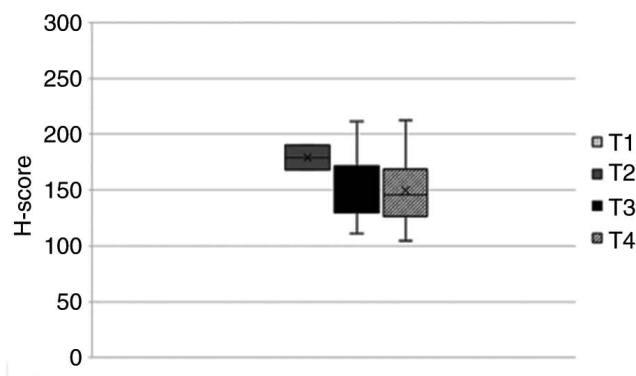

D

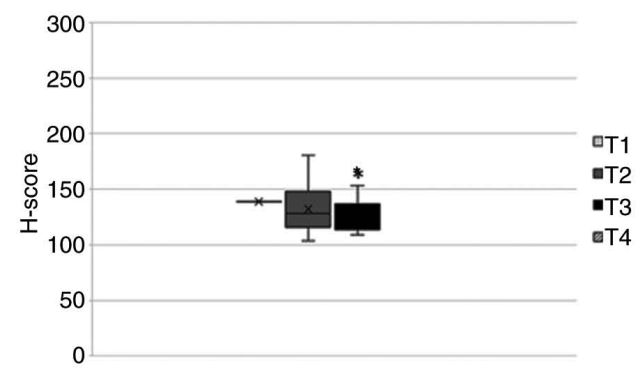

$\mathrm{F}$

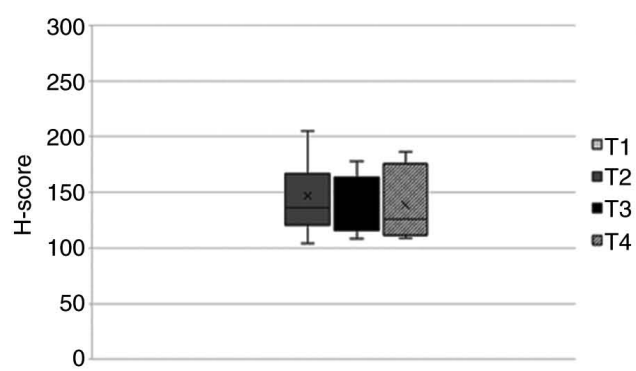

Figure 6. Association between $\mathrm{H}$-score of nTCTP and T stage $\left({ }^{*} \mathrm{P}<0.05,{ }^{* *} \mathrm{P}<0.01\right)$ for $(\mathrm{A})$ breast cancer, (B) colon cancer, (C) kidney cancer, (D) lung cancer, (E) pancreas cancer, and $(\mathrm{F})$ prostate cancer. nTCTP, nuclear translationally controlled tumor protein; cTCTP, cytoplasmic translationally controlled tumor protein.

with T stage. The expression patterns were more heterogeneous compared to those in shown in Fig. 6. For kidney cancer and pancreatic cancer, a slight non-significant increase in cTCTP expression associated with T1-T2 was observed. The results from the other tumor types were not conclusive.

The association of nTCTP with tumor grade (Fig. 8) revealed more heterogeneous expression patterns compared to those shown in Fig. 6. For kidney cancer, a significant increase in nTCTP expression associated with the increasing tumor grade (grade 1-4) was observed. For colon cancer, nTCTP expression significantly increased for grade 3 tumors compared to grade 1 or 2 tumors. However, no difference between grade 1 and 2 tumors was found. nTCTP expression in lung cancer significantly decreased with the higher tumor grade. For breast, pancreas and prostate cancer, no significant change in nTCTP expression was observed for the association with tumor grade. The investigation of cTCTP and tumor grade revealed a significant increase in cTCTP expression associated with tumor grade 1-3 for kidney cancer (Fig. 9). No significant changes were observed for the other tumor types analyzed.

Furthermore, the association between nTCTP and cTCTP expression, and metastatic status in kidney cancer was investigated. As shown in Fig. 10, the presence of metastases in distant organs led to significantly higher expression levels of both, nTCTP and cTCTP. Similar observations were found regarding the nodal status (Fig. 11). The expression of nTCTP was significantly elevated in tumors with a nodal status above N1. This was also found for cTCTP. However, nTCTP and cTCTP were not differentially expressed in tumors of status N0 or N1.

\section{Discussion}

TCTP is an evolutionary highly conserved multifunctional protein with diverse roles in key regulatory processes such as cell growth, protein synthesis, cell cycle progression, apoptosis, immune response and cancer. It can be found in all Eukaryotic species (35) and interacts with a wide range of different proteins (3). Previous results have revealed its role in tumor reversion (26) and the induction of pluripotent stem cells (36). TCTP downregulation leads to reprogramming cells either into apoptosis or tumor reversion (37). The protein is highly expressed in human cancer (38). Tumor reversion is clinically attractive as target for cancer treatment (39). Advances in oncology have led to higher life expectancies, resulting in increased overall cancer incidences in both developed and developing countries (40). High numbers of different malignancies cause enormous costs and economic damages throughout the world (41-43). Cancer research is continuously aiming to identify novel targets for new active compounds. However, classical chemotherapy remains a mainstay in tumor therapy according to the cancer treatment 
A

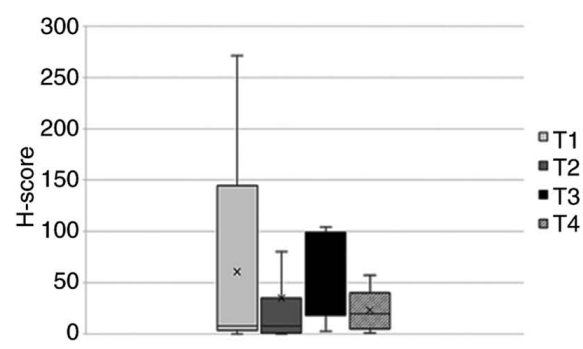

C

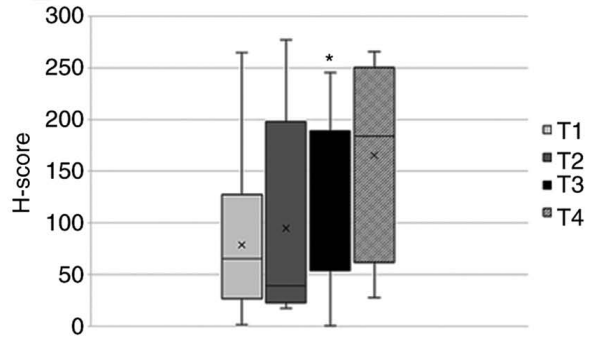

$\mathrm{E}$

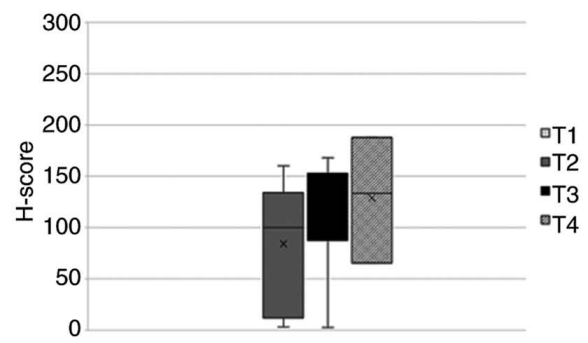

B

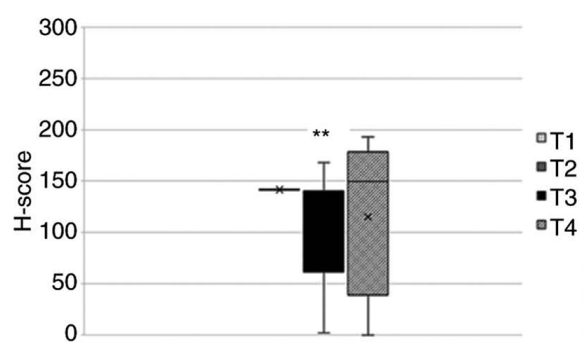

D

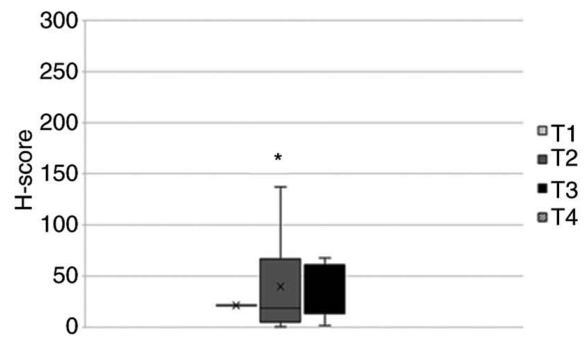

$\mathrm{F}$

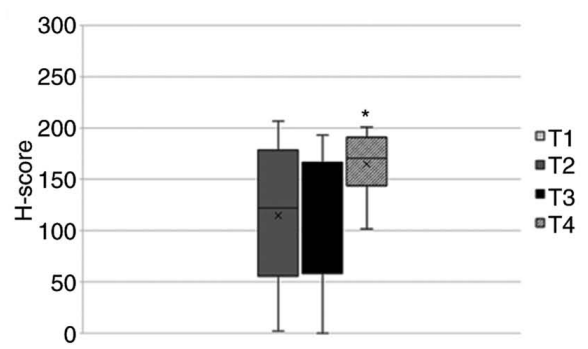

Figure 7. Association between the H-score of cTCTP and T stage for (A) breast cancer, (B) colon cancer, (C) kidney cancer, (D) lung cancer, (E) pancreas cancer, and (F) prostate cancer. cTCTP, cytoplasmic translationally controlled tumor protein $\left({ }^{*} \mathrm{P}<0.05,{ }^{* *} \mathrm{P}<0.01\right)$.

A

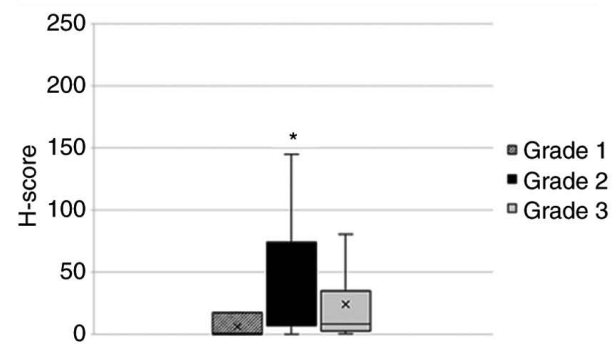

C

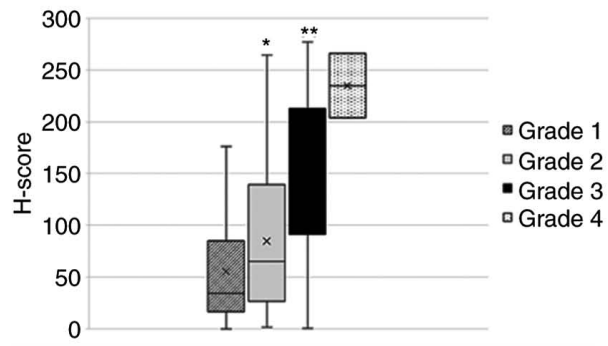

$\mathrm{E}$

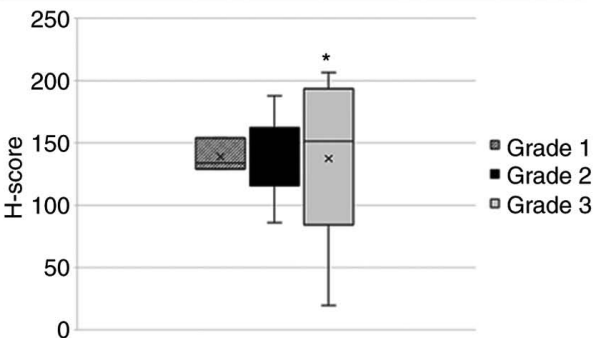

B

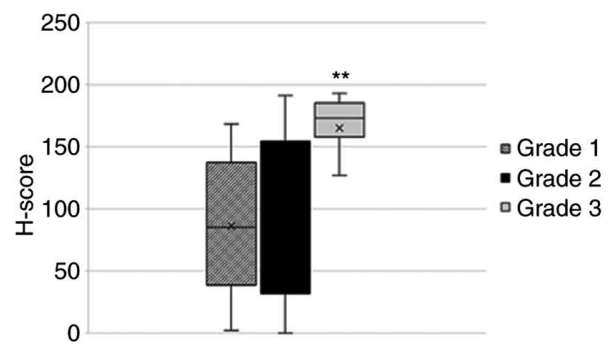

D

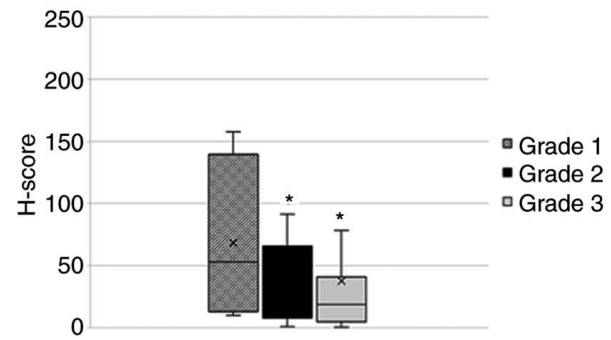

$\mathrm{F}$

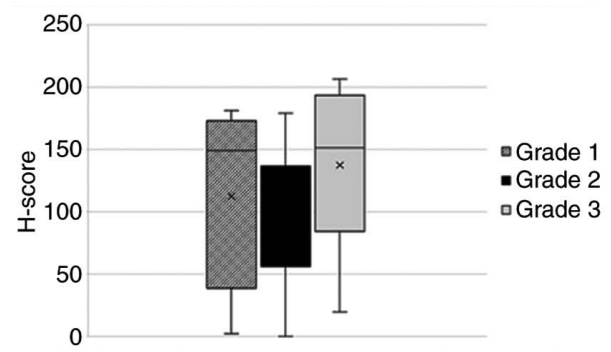

Figure 8. Association between H-score of nTCTP and tumor grade for (A) breast cancer, (B) colon cancer, (C) kidney cancer, (D) lung cancer, (E) pancreas cancer, and (F) prostate cancer. nTCTP, nuclear translationally controlled tumor protein $\left({ }^{*} \mathrm{P}<0.05,{ }^{* *} \mathrm{P}<0.01\right)$. 
A

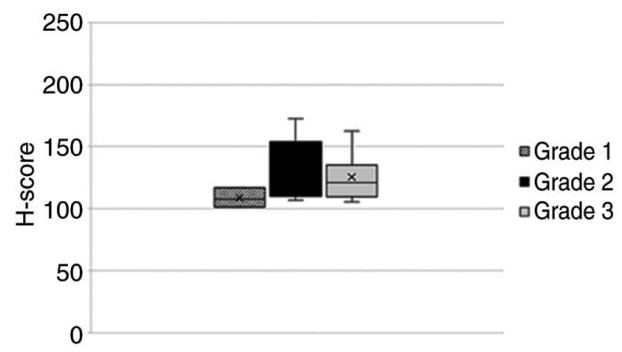

C

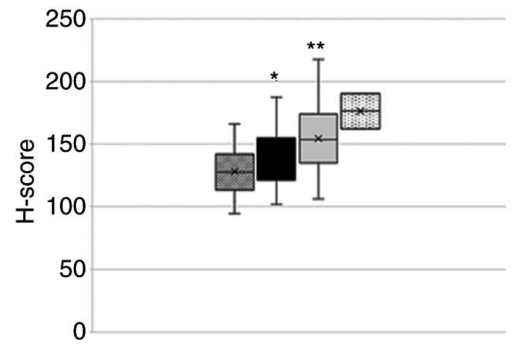

$\mathrm{E}$

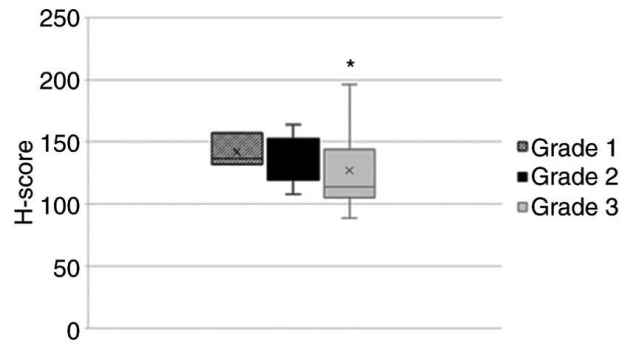

B

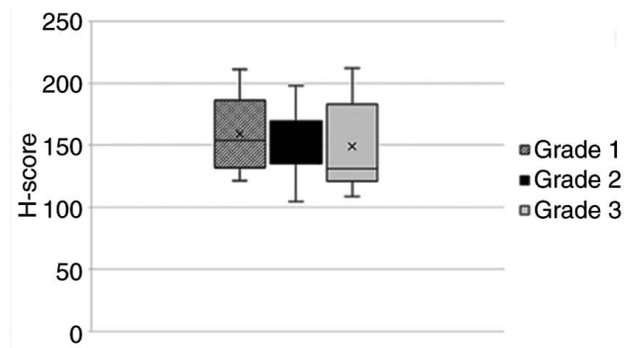

D

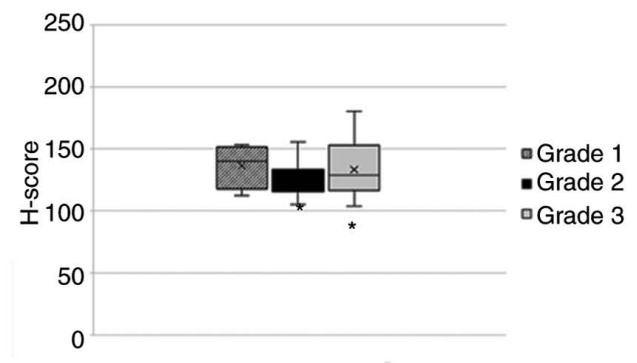

$\mathrm{F}$

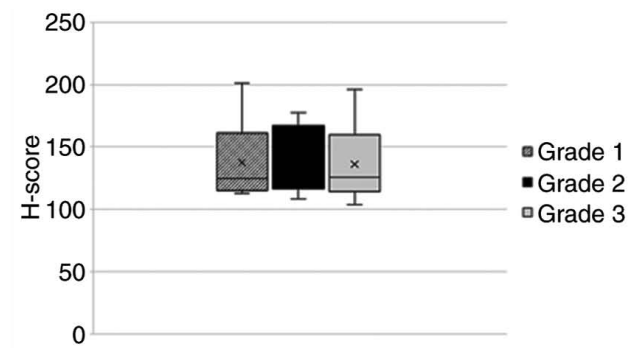

Figure 9. Association between H-score of cTCTP and tumor grade for (A) breast cancer, (B) colon cancer, (C) kidney cancer, (D) lung cancer, (E) pancreas cancer, and (F) prostate cancer. cTCTP, cytoplasmic translationally controlled tumor protein $\left({ }^{*} \mathrm{P}<0.05,{ }^{* *} \mathrm{P}<0.01\right)$.
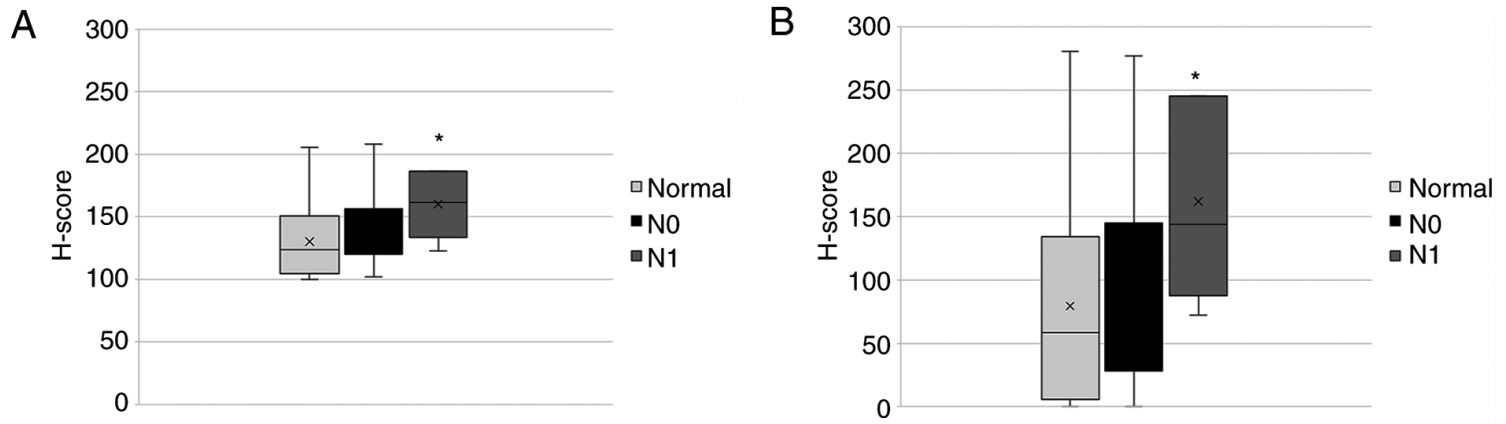

Figure 10. Association between H-score of (A) nTCTP and (B) cTCTP and metastatic status for kidney cancer. nTCTP, nuclear translationally controlled tumor protein; cTCTP, cytoplasmic translationally controlled tumor protein ( $\mathrm{P}<0.05)$.
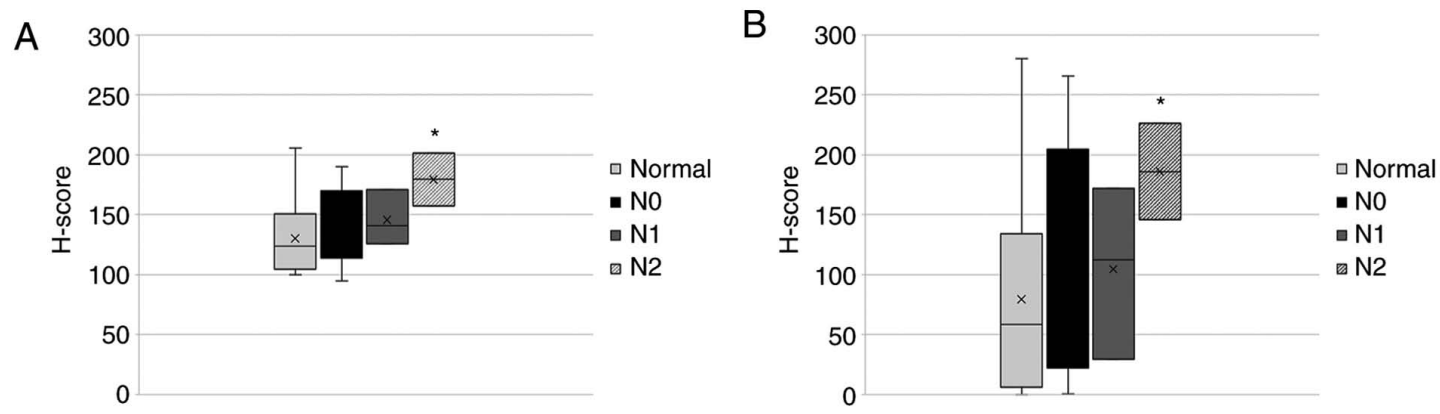

Figure 11. Association between H-score of (A) nTCTP and (B) cTCTP and nodal status for kidney cancer. nTCTP, nuclear translationally controlled tumor protein; cTCTP, cytoplasmic translationally controlled tumor protein ( $\mathrm{P}<0.05)$. 
guidelines of leading health authorities. A frequent problem is the non-sufficient selectivity between tumor and normal cells, which causes severe side-effects, such as hair loss, vomiting, anemia and bone marrow suppression (44). In addition, drug resistance limits the therapeutic success and quality of life of patients (45). Therefore, there is an urgent necessity to identify new targets for more effective tumor therapies. The present study was conducted to evaluate both the role of TCTP as a novel target and prognostic factor in cancer therapy. To date, there are only limited studies available on TCTP as a prognostic factor, at least to the best of our knowledge $(31,33,46,47)$. However, a comprising overview of the relevance of TCTP and clinical prognosis, such as the one presented herein was lacking.

For breast cancer, the present study observed a significantly shorter overall survival time (-12.35 months, $\mathrm{P}<0.001)$, if TCTP was highly expressed compared to a low TCTP expression in one dataset. The smaller dataset 'TCGA Breast' exhibited the same tendency (overall survival time reduction of 4.74 months, $\mathrm{P}=0.333$ ). However, this association was not significant. TCTP has been previously reported as a prognostic factor (25), which was validated by the present study. In lung cancer, the high expression of TCTP was accompanied by a decrease of 30.29 overall survival months $(\mathrm{P}<0.001)$. For two smaller studies, the change in survival time was not significant. The role of TCTP as a prognostic factor has been discussed (48); however, no scientific study has been reported as yet, at least to the best of our knowledge. In ovarian cancer, a high TCTP expression was associated with decreased overall survival times. Patients with a high TCTP status lived $11.75(\mathrm{P}=0.042)$ resp. $11.69(\mathrm{P}=0.019)$ months shorter compared to patients with a low TCTP expression status. An immunohistological study on 119 ovarian cancer cases stressed the role of TCTP as promotor of tumor progression (33). The present study complemented that study by investigating 798 tumor cases. A high TCTP expression was accompanied by a survival time that was 33.13 months shorter $(\mathrm{P}<0.001)$ in prostate cancer. By now, no comparable study has been conducted for prostate cancer. In lymphoma, a reverse effect was observed. A high TCTP expression was significantly associated $(\mathrm{P}=0.016)$ with a prolonged survival (+37.63 months), if the median was selected as the expression cut-off. As large B- cell lymphoma (49) was the only non-solid malignancy we analyzed; a different clinical outcome was to be expected.

Furthermore, the present study examined TCTP protein expression in tissues of 24 tumor types (adipose, adrenal, bladder, brain, colon, duodenum, esophagus, fallopian tube, gall bladder, kidney, liver, lung, ovarian, paratoid, prostate, rectum, skin, small intestine, soft tissue, stomach, testis, throat, tonsil and uterine cancer) and observed elevated cytoplasmic TCTP expression in all of these (Fig. 4). Differential analysis of nTCTP and cTCTP revealed mostly a cytoplasmic TCTP localization in breast, colon, kidney, lung, pancreas and prostate cancer (Fig. 5). The analysis of nTCTP and TNM stage did not reveal any significant results. However, a tendency towards a high TCTP expression accompanied by a high TNM stage was observed in breast, kidney and pancreatic cancer (Fig. 6). As regards cTCTP, the same tendency was observed in kidney and pancreatic cancer (Fig. 7). The tumor grades of the cancer types mentioned above were examined and a significant
$(\mathrm{P}=0.033)$ increase in nTCTP expression was observed with the increasing tumor grade in kidney cancer. This result was even more significant for cTCTP $(\mathrm{P}=0.028)$. In colon cancer, nTCTP expression was significantly higher $(\mathrm{P}=0.009)$ in samples from patients with grade 3 compared to those with grade 1 and 2 disease. The other tissues did not exhibit any significant associations.

The present study further analyzed the metastatic status and nodal status of kidney cancer tissue samples. Tissues of patients with distant metastases exhibited a significantly higher expression of both nTCTP $(\mathrm{P}=0.043)$ and cTCTP $(\mathrm{P}=0.042)$ compared to those without metastases. Previously, a high TCTP expression has only been only linked by other authors to the metastases of gallbladder carcinoma (50) colorectal carcinoma (51), melanoma (52), cholangiocarcinoma (38) and glioma (53).

As regards the nodal status, nTCTP was significantly more expressed $(\mathrm{P}=0.028)$ in patients with $\mathrm{N} 2$ status compared to N0 or N1 status. Differences in nTCTP expression were not observed for tissues from patients with N0 or N1 status. The same result was observed for cTCTP expression. cTCTP was significantly $(\mathrm{P}=0.036)$ more expressed in kidney tumor tissue from patients with $\mathrm{N} 2$ status compared to N0 or N1 status. Differences between samples from patients with $\mathrm{N} 0$ or N1 status were not detected. To our knowledge, an association between TCTP expression and the nodal status has not been previously described.

In conclusion, the present study demonstrates that TCTP expression was higher in malignant tissue compared to normal tissue in 24 cancer types. Both mRNA and protein expression reflected the prognostic value of TCTP for cancer patients. In breast, lung ovarian and prostate cancer, elevated TCTP mRNA levels were associated with shorter survival times. A high TCTP expression, particularly in the nucleus, corresponded with a poor prognosis, represented not only by tumor stage and grade, but also by the presence of metastases and cancer in nearby lymph nodes in kidney cancer.

\section{Acknowledgements}

Not applicable.

\section{Funding}

No funding was received.

\section{Availability of data and materials}

The datasets used and/or analyzed during the current study are available from the corresponding author on reasonable request.

\section{Authors' contributions}

NF performed the experiments, and conducted the statistical analyses, and wrote the draft of the manuscript NF and TE set up the concept and designed the study. TE supervised the project and corrected the manuscript. MEMS was involved in the conception and conduction of the immunohistological experiments. WR and EL delivered tissue arrays and corrected the manuscript. All authors read and approved the final manuscript. 


\section{Ethics approval and consent to participate}

Tissue arrays were provided by the Tissue Bank of the Institute of Pathology, University Medical Center of the Johannes-Gutenberg-Universität, Mainz) with ethical approval from the Ethics Committee of the State Authorization Association for Medical Issues (Landesärztekammer) Rheinland Pfalz to WR (October 2, 2015; Ref. 837.031 9799) and to TE (March 22, 2018; Ref. 2018-13179). The patients gave written informed consent for evaluation of tumor material and publication of data generated from these investigations prior to participation.

\section{Patient consent for publication}

Not applicable.

\section{Competing interests}

The authors declare that they have no competing interests.

\section{References}

1. Acunzo J, Baylot V, So A and Rocchi P: TCTP as therapeutic target in cancers. Cancer Treat Rev 40: 760-769, 2014.

2. Bommer UA and Thiele BJ: The translationally controlled tumour protein (TCTP). Int J Biochem Cell Biol 36: 379-385, 2004.

3. Li S and Ge F: Current understanding of the TCTP interactome. Results Probl Cell Differ 64: 127-136, 2017.

4. Assrir N, Malard F and Lescop E: Structural Insights into TCTP and its interactions with ligands and proteins. Results Probl Cell Differ 64: 9-46, 2017.

5. Seo EJ, Fischer N and Efferth T: Role of TCTP for cellular differentiation and cancer therapy. Results Probl Cell Differ 64: 263-281, 2017

6. Kubiak JZ and Kloc M: Elusive role of TCTP protein and mRNA in cell cycle and cytoskeleton regulation. Results Probl Cell Differ 64: 217-225, 2017.

7. Betsch L, Boltz V, Brioudes F, Pontier G, Girard V, Savarin J, Wipperman B, Chambrier P, Tissot N, Benhamed M, et al: TCTP and CSN4 control cell cycle progression and development by regulating CULLIN1 neddylation in plants and animals. PLoS Genet 15: e1007899, 2019.

8. Jojic B, Amodeo S and Ochsenreiter T: The translationally controlled tumor protein TCTP is involved in cell cycle progression and heat stress response in the bloodstream form of Trypanosoma brucei. Microb Cell 5: 460-468, 2018.

9. Koziol MJ and Gurdon JB: TCTP in development and cancer. Biochem Res Int 2012: 105203, 2012.

10. Chen SH, Wu PS, Chou CH, Yan YT, Liu H, Weng SY and Yang-Yen HF: A knockout mouse approach reveals that TCTP functions as an essential factor for cell proliferation and survival in a tissue- or cell type-specific manner. Mol Biol Cell 18 2525-2532, 2007.

11. Kubiak JZ, Bazile F, Pascal A, Richard-Parpaillon L, Polanski Z, Ciemerych MA and Chesnel F: Temporal regulation of embryonic M-phases. Folia Histochem Cytobiol 46: 5-9, 2008.

12. Hsu YC, Chern JJ, Cai Y, Liu M and Choi KW: Drosophila TCTP is essential for growth and proliferation through regulation of dRheb GTPase. Nature 445: 785-788, 2007.

13. Cans C, Passer BJ, Shalak V, Nancy-Portebois V, Crible V, Amzallag N, Allanic D, Tufino R, Argentini M, Moras D, et al: Translationally controlled tumor protein acts as a guanine nucleotide dissociation inhibitor on the translation elongation factor eEF1A. Proc Natl Acad Sci USA 100: 13892-13897, 2003

14. Bazile F, Pascal A, Arnal I, Le Clainche C, Chesnel F and Kubiak JZ: Complex relationship between TCTP, microtubules and actin microfilaments regulates cell shape in normal and cancer cells. Carcinogenesis 30: 555-565, 2009.

15. Tsarova K, Yarmola EG and Bubb MR: Identification of a cofilin-like actin-binding site on translationally controlled tumor protein (TCTP). FEBS Lett 584: 4756-4760, 2010.
16. Mishra DK, Srivastava P, Sharma A, Prasad R, Bhuyan SK, Malage R, Kumar P and Yadava PK: Translationally controlled tumor protein (TCTP) is required for TGF- $\beta 1$ induced epithelial to mesenchymal transition and influences cytoskeletal reorganization. Biochim Biophys Acta Mol Cell Res 1865: 67-75, 2018.

17. Wu W, Wu B, Ye T, Huang H, Dai C, Yuan J and Wang W: TCTP is a critical factor in shrimp immune response to virus infection. PLoS One 8: e74460, 2013.

18. Taylor KJ, Van TT, MacDonald SM, Meshnick SR, Fernley RT, Macreadie IG and Smooker PM: Immunization of mice with plasmodium TCTP delays establishment of plasmodium infection. Parasite Immunol 37: 23-31, 2015.

19. MacDonald SM, Rafnar T, Langdon J and Lichtenstein LM: Molecular identification of an IgE-dependent histamine-releasing factor. Science 269: 688-690, 1995.

20. Li F, Zhang D and Fujise K: Characterization of fortilin, a novel antiapoptotic protein. J Biol Chem 276: 47542-47549, 2001.

21. Yang Y, Yang F, Xiong Z, Yan Y, Wang X, Nishino $M$, Mirkovic D, Nguyen J, Wang $\mathrm{H}$ and Yang XF: An N-terminal region of translationally controlled tumor protein is required for its antiapoptotic activity. Oncogene 24: 4778-4788, 2005.

22. Bommer UA, Vine KL, Puri P, Engel M, Belfiore L, Fildes K, Batterham M, Lochhead A and Aghmesheh M: Translationally controlled tumour protein TCTP is induced early in human colorectal tumours and contributes to the resistance of HCT116 colon cancer cells to 5-FU and oxaliplatin. Cell Commun Signal 15: 9, 2017.

23. Li S, Chen M, Xiong Q, Zhang J, Cui Z and Ge F: Characterization of the translationally controlled tumor protein (TCTP) interactome reveals novel binding partners in human cancer cells. J Proteome Res 15: 3741-3751, 2016.

24. Tuynder M, Susini L, Prieur S, Besse S, Fiucci G, Amson R and Telerman A: Biological models and genes of tumor reversion: Cellular reprogramming through tpt1/TCTP and SIAH-1. Proc Natl Acad Sci USA 99: 14976-14981, 2002.

25. Amson R, Karp JE and Telerman A: Lessons from tumor reversion for cancer treatment. Curr Opin Oncol 25: 59-65, 2013.

26. Tuynder M, Fiucci G, Prieur S, Lespagnol A, Géant A, Beaucourt S, Duflaut D, Besse S, Susini L, Cavarelli J, et al: Translationally controlled tumor protein is a target of tumor reversion. Proc Natl Acad Sci USA 101: 15364-15369, 2004.

27. Telerman A and Amson R: The molecular programme of tumour reversion: The steps beyond malignant transformation. Nat Rev Cancer 9: 206-216, 2009.

28. Ferlay J, Colombet M, Soerjomataram I, Mathers C, Parkin DM, Piñeros M, Znaor A and Bray F: Estimating the global cancer incidence and mortality in 2018: GLOBOCAN sources and methods. Int J Cancer 144: 1941-1953, 2019.

29. Mattiuzzi C and Lippi G: Current cancer epidemiology. J Epidemiol Glob Health 9: 217-222, 2019.

30. Vasan N, Baselga J and Hyman DM: A view on drug resistance in cancer. Nature 575: 299-309, 2019.

31. Miao X, Chen YB, Xu SL, Zhao T, Liu JY, Li YR, Wang J, Zhang J and Guo GZ: TCTP overexpression is associated with the development and progression of glioma. Tumour Biol 34: 3357-3361, 2013.

32. Amson R, Pece S, Marine JC, Di Fiore PP and Telerman A: TPT1/ TCTP-regulated pathways in phenotypic reprogramming. Trends Cell Biol 23: 37-46, 2013.

33. Chen C, Deng Y, Hua M, Xi Q, Liu R, Yang S, Liu J, Zhong J, Tang M, Lu S, et al: Expression and clinical role of TCTP in epithelial ovarian cancer. J Mol Histol 46: 145-156, 2015.

34. Michaelsen FW, Saeed ME, Schwarzkopf J and Efferth T: Activity of Artemisia annua and artemisinin derivatives, in prostate carcinoma. Phytomedicine 22: 1223-1231, 2015.

35. Koo N, Shin AY, Oh S, Kim H, Hong S, Park SJ, Sim YM, Byeon I, Kim KY, Lim YP, et al: Comprehensive analysis of translationally controlled tumor protein (TCTP) provides insights for lineage-specific evolution and functional divergence. PLoS One 15: e0232029, 2020.

36. Brioudes F, Thierry AM, Chambrier P, Mollereau B and Bendahmane M: Translationally controlled tumor protein is a conserved mitotic growth integrator in animals and plants. Proc Natl Acad Sci USA 107: 16384-16389, 2010.

37. Proietti S, Cucina A, Pensotti A, Biava PM, Minini M, Monti N, Catizone A, Ricci G, Leonetti E, Harrath AH, et al: Active fraction from embryo fish extracts induces reversion of the malignant invasive phenotype in breast cancer through down-regulation of TCTP and modulation of E-cadherin/ $\beta$-catenin pathway. Int $\mathrm{J}$ Mol Sci 20: 2151, 2019. 
38. Phanthaphol N, Techasen A, Loilome W, Thongchot S, Thanan R, Sungkhamanon S, Khuntikeo N, Yongvanit P and Namwat N: Upregulation of TCTP is associated with cholangiocarcinoma progression and metastasis. Oncol Lett 14: 5973-5979, 2017.

39. Powers S and Pollack RE: Inducing stable reversion to achieve cancer control. Nat Rev Cancer 16: 266-270, 2016.

40. Gu X, Zheng R, Xia C, Zeng H, Zhang S, Zou X, Yang Z, Li H and Chen W: Interactions between life expectancy and the incidence and mortality rates of cancer in China: A population-based cluster analysis. Cancer Commun (Lond) 38: 44, 2018.

41. Luengo-Fernandez R, Leal J, Gray A and Sullivan R: Economic burden of cancer across the European Union: A population-based cost analysis. Lancet Oncol 14: 1165-1174, 2013.

42. Mariotto AB, Yabroff KR, Shao Y, Feuer EJ and Brown ML: Projections of the cost of cancer care in the United States: 2010-2020. J Natl Cancer Inst 103: 117-128, 2011.

43. Sankaranarayanan R, Ramadas K and Qiao Yl: Managing the changing burden of cancer in Asia. BMC Med 12: 3, 2014.

44. Weber GF: DNA Damaging Drugs. In: Molecular Therapies of Cancer. Weber GF (ed). Springer, Cham, International Publishing, pp9-112, 2015.

45. Hwang SY, Chang SJ and Park BW: Does chemotherapy really affect the quality of life of women with breast cancer? J Breast Cancer 16: 229-235, 2013.

46. Lucibello M, Adanti S, Antelmi E, Dezi D, Ciafrè S, Carcangiu ML, Zonfrillo M, Nicotera G, Sica L, De Braud F and Pierimarchi P: Phospho-TCTP as a therapeutic target of Dihydroartemisinin for aggressive breast cancer cells. Oncotarget 6: 5275-5291, 2015.

47. Ramani P, Nash R, Sowa-Avugrah E and Rogers C: High levels of polo-like kinase 1 and phosphorylated translationally controlled tumor protein indicate poor prognosis in neuroblastomas. J Neurooncol 125: 103-111, 2015.
48. Sun R, Lu X, Gong L and Jin F: TCTP promotes epithelial-mesenchymal transition in lung adenocarcinoma. Onco Targets Ther 12: 1641-1653, 2019.

49. Rosenwald A, Wright G, Chan WC, Connors JM, Campo E, Fisher RI, Gascoyne RD, Muller-Hermelink HK, Smeland EB, Giltnane JM, et al: The use of molecular profiling to predict survival after chemotherapy for diffuse large-B-cell lymphoma. N Engl J Med 346: 1937-1947, 2002.

50. Zhang F, Ma Q, Xu Z, Liang H, Li H, Ye Y, Xiang S, Zhang Y, Jiang L, Hu Y, et al: Dihydroartemisinin inhibits TCTP-dependent metastasis in gallbladder cancer. J Exp Clin Cancer Res 36: 68 2017.

51. Xiao B, Chen D, Luo S, Hao W, Jing F, Liu T, Wang S, Geng Y, $\mathrm{Li} \mathrm{L}, \mathrm{Xu} \mathrm{W}$, et al: Extracellular translationally controlled tumor protein promotes colorectal cancer invasion and metastasis through $\mathrm{Cdc} 42 / \mathrm{JNK} / \mathrm{MMP} 9$ signaling. Oncotarget 7 : 50057-50073, 2016.

52. Bae SY, Kim HJ, Lee KJ and Lee K: Translationally controlled tumor protein induces epithelial to mesenchymal transition and promotes cell migration, invasion and metastasis. Sci Rep 5: $8061,2015$.

53. Jin H, Zhang X, Su J, Teng Y, Ren $\mathrm{H}$ and Yang L: RNA interference-mediated knockdown of translationally controlled tumor protein induces apoptosis, and inhibits growth and invasion in glioma cells. Mol Med Rep 12: 6617-6625, 2015.

This work is licensed under a Creative Commons Attribution-NonCommercial-NoDerivatives 4.0 International (CC BY-NC-ND 4.0) License. 